\title{
Dimensiones referencial, imaginaria y pragmática del tiempo en la modernidad y en la postmodernidad
}

\author{
José Ángel Bergua Amores \\ Escuela Universitaria de Estudios Empresariales \\ Ronda M isericordia, 1. 22001 H uesca. Spain
}

\begin{abstract}
Resumen
En forma de ensayo, el presente artículo propone analizar desde un punto de vista semiótico el tiempo de la modernidad y de su crisis según tres dimensiones: una referencial o identitaria, que atiende a los sistemas de referencias utilizados para medirlo, otra imaginaria, que le otorga cualidad y afecto, y finalmente otra pragmática, que alude a su performatividad. En la modernidad la dimensión referencial debe dar cuenta del contexto social en el que toman protagonismo el reloj y el mecanicismo clásico, la imaginaria, de los tiempos que van del eterno retorno al existencialismo, y la pragmática, del modo como al gunos relojes centrales sincronizan los tiempos de las sociabilidades periféricas. En la actual crisis de la modernidad pensar el tiempo exige poder dar cuenta de sus líneas de fuga, y para ello resultan útiles el paradigma de la irreversibilidad dinámica en la dimensión referencial, ciertas imágenes valorizadoras del presente en la dimensión imaginaria y un nuevo modo de valorar la asincronía en la dimensión pragmática.
\end{abstract}

Palabras clave: tiempo, postmodernidad, imaginario, complejidad.

\begin{abstract}
M odernity and Postmodernity
This article sets out to analyse the time of modernity and its crisis acording to three dimension from the semiotic point of view: a referential or identity that takes care of the reference system used to measure it, another imaginary that gives quality and affecttion, and finally one that alluds its performance. The referential dimension in modernity, should take into consideration the social context in wich the clock and the mechanicism play the leading role, the imaginary of times that range from etern return to existencialism, and he pragmatic mode of some crisis of modernity, to think time equires considering its scape times, and certain image valueer of the present in the imaginary dimension, and the reflection about the social conditions of the asincronicity in the pragmatic dimension.
\end{abstract}

Key words: time, postmodernity, imagery, complexity.

\section{Sumario}

1. Dimensión referencial: el reloj y el paradigma mecanicista

2. Dimensión imaginaria: del eterno retorno al utopismo
3. Dimensión pragmática: la sincronización

4. Del tiempo instituido moderno al tiempo instituyente postmoderno

Bibliografía 
Aunque cualquier temporalidad es, en primera instancia, autoal teración constante, simple devenir, esa experiencia es en realidad producto de una «puntuación» previa que ha «distinguido» el devenir de la eternidad y ha «indicado»1 que uno de los dos lados, el devenir, es el relevante para la observación ${ }^{2}$. Al margen de esa operación previa, cada sociedad o período histórico instituye y puntúa, sobre ese devenir, uno o varios tiempos explícitos ${ }^{3}$ que, en tanto signos, tienen varias dimensiones (C astroriadis, 1989: 71-86): una referencial 0 identitaria, que tiene que ver con el sistema de medida utilizado para conte ner el flujo del devenir, es el tiempo calendario; otra imaginaria o de significación, en relación de presunción recíproca con la anterior, que semantiza períodos y límites concediendo cualidad y afecto al tiempo, y otra pragmática, que construye temporalidades a un nivel superior sincronizando, es decir, permitiendo que ciertas partes o esferas dominantes de la sociedad controlen a sus correspondientes partes dominadas ${ }^{4}$. Pues bien, partiendo de esta distinción

1. Relaciono el concepto batesoniano de «puntuación» con los de «distinción»e «indicación» propuestos por Spencer Brown, y lo hago siguiendo las sugerencias de Keeney (1987): «el empleo de la distinción para crear una indicación es una manera de definir la puntuación» (p. 40). «Spencer Brown enuncia que un universo se engendra cuando se separa o aparta de un espacio y que los límites pueden trazarse en cualquier lugar que nos plazca; de este modo, a partir del acto creativo primordial de establecer distinciones pueden engendrarse infinitos mundos posibless (p. 33). Por lo tanto, para conocer cualquier sistema debemos apreciar qué distinciones están en la base de su creación, y qué lados separados por ese movimiento fueron elegidos o indicados.

2. Antes incluso de la distinción tiempo/eternidad interviene la distinción fundamental «ser»/《no-ser»y la indicación de uno de sus dos lados como relevante. En O ccidente fue Parménides quien efectuó la operación, despejando así el camino para el pensamiento y estilo de vida que no son habituales: «una vez decidido, como era necesario, el abandono de uno de los dos caminos (el del no ser) por su carácter de impensable e innombrable - porque no es el verdadero- habrá que considerar el otro (el del ser) como real y auténtico» (Parménides/H eráclito, 1983: 53). A esta indicación o preferencia por el «ser» se puede oponer la observación de Lao Tse (1985: 104): «aunque con arcilla se fabrican las vasijas en ellas lo útil es la nada (su oquedad)», con la que se relativiza la importancia del ser; o la de Cioran (1988: 134), más drástica, que apuesta por el «no-ser»: «sólo es subversivo el espíritu que pone en tela de juicio la obligación de existir; todos los otros, empezando por el anarquista, pactan con el orden establecido». Pues bien, después de esta distinción, «ser»/《no-ser», la indicación del «ser» da lugar a la distinción segunda, «tiempo»/ «eternidad» (Eliade, 1992, 1994).

3. García C alvo (1993) ha denunciado las maquinaciones científicas e ideológicas con las que se cambia ese devenir indefinido e infinito por el Tiempo para construir la Realidad.

4. M e baso aquí en la teoría de redes de Petri expuesta por N avarro (1994: 351-77). Se parte de la crítica del tiempo newtoniano según las sugerencias de la teoría especial de la relatividad, y, por ello, de la consideración de que, por oposición al tiempo absoluto y abstracto clásico, que bate instantes válidos para todo el universo, en real idad cual quier suceso bate su propio instante. Según esto, son «síncronos» «los sucesos cuya secuencia está controlada por un mismo reloj» (se trata de tiempos distintos ordenados o asimilados a una misma secuencia temporal), son «isócronos» los instantes batidos por dos o más relojes que coinciden en un mismo suceso (se trata del principio de sincronicidad chino, que indaga «qué sucede con qué», tan diferente del principio de causal idad moderno que se pregunta «qué sucede despues de qué»), y son «asíncronos» los instantes independientes y carentes de relación causal de dos o más 
voy a ensayar el análisis del tiempo que se instituyó en la modernidad y del que puede estar emergiendo en la postmodernidad tras el derrumbe de los metarrelatos científicos e ideológicos modernos (Lyotard, 1987).

\section{Dimensión referencial: el reloj y el paradigma mecanicista}

Por ser un asunto muy tratado, no realizaré un análisis de las referencias utilizadas para medir el tiempo. Sin embargo, sí prestaré atención al cambio de paradigmas encargado de contenerlas que sobrevino en la modernidad como consecuencia del nuevo interés que despertó entre científicos y burgueses su control. En este sentido conviene comenzar recordando, con G iddens (1993: 28-31), que en la premodernidad «la estimación del tiempo que configuraba la base de la vida cotidiana vinculaba siempre, al menos para la mayoría de la población, el tiempo con el espacio, y (que) era normalmente imprecisa y variable» debido a que «el cuándo estaba casi universalmente conectado al dónde». Estos intervalos espaciotemporal es habían sido estabilizados y precisados mediante la fijación a determinados sistemas de medida que eran, a la vez, espejo tanto del macrocosmos del universo como del microcosmos social. En concreto, en el mundo mediterráneo hubo dos calendarios, uno de origen indoeuropeo y de corte patriarcal basado en el sistema de numeración decimal que dio lugar al año solar de diez meses y otro más antiguo, matriarcal, relacionado con un sistema de numeración sexagesimal del que resulto el año lunar de doce (D urand, 1984: 327). Este anudamiento del macrocosmos y del microcosmos en un orden temporal fue deshecho por la modernidad con dos intervenciones: la del tiempo serializado del reloj, que separó el tiempo de su contexto social, y la del tiempo reversible de la mecánica newtoniana, que separó el tiempo de los ciclos cósmicos. Aunque los dos tiempos fueron declarados objetivos, mostraré que en realidad fueron aliados de la nueva sociedad que se instituyó en la modernidad.

Los primeros relojes datan del siglo XIII, y en el siglo XIV, a pesar de ser todavía rudimentarios (sólo tenían manecillas horarias y carecían de esfera), ya eran utilizados en los monasterios. Sin embargo, fue con su perfeccionamiento y la generalización de su uso a finales del siglo XVIII como el tiempo comenzó a ser abstraído de su contexto social. Según Giddens (1993: 29), el «vaciado» del tiempo y del espacio formó parte de una más vasta operación de «desanclaje», por la que las relaciones sociales fueron despegadas de sus contextos locales, lo que permitió su reestructuración en los intervalos espaciotemporales producidos por la nueva y racional organización de la sociedad. U na de las dimensiones de esta nueva organización (junto con el industrialismo transformador de la naturale-

sucesos batidos por distintos rel ojes. Pues bien, la sincronización consiste en someter al imperio de un reloj central arbitrario los instantes de los sucesos batidos por otros relojes. M ás exactamente, los procesos asincrónicos son sincronizados mediante una «transferencia de información» (p. 360), operación que aúna dos movimientos: uno de extracción de información y otro de introducción de neguentropía (I báñez, 1990: 4-5). 
za, el capitalismo acumulador de valor, el monopolio de la violencia, el proceso civilizador encargado de contener los instintos, etc.) fue el sistema disciplinario (p. 64), encargado del «control minucioso de las operaciones del cuerpo» para garantizar «a sujeción constante de sus fuerzas» e imponerles «una relación de docilidad-utilidad» (Foucault, 1986: 141). En relación con el control de las actividades, ya las comunidades monásticas habían sido precursoras en la premodernidad del establecimiento de ritmos y de la regulación de los ciclos de repetición que luego copiaron talleres, colegios y hospitales. Sin embargo, con la modernidad estas exigencias serán generalizadas a otras instituciones e intensificadas al menos en cuatro aspectos: la elaboración temporal del acto mediante la imposición desde el exterior de programas y ritmos colectivos, el establecimiento a nivel individual de sistemas secuenciales de gestos 5 y la utilización exhaustiva del tiempo para extraer de todo movimiento «cada vez más instantes disponibles y de cada instante cada vez más fuerzas útiles» (p. 158). El más digno heredero de esta tradición que aspiró al control exhaustivo de los sujetos en su dimensión temporal fue sin duda el taylorismo, que asumió, «como una necesidad absoluta para una adecuada administración, la imposición al obre ro de la manera precisa en que debía ser ejecutado el trabajo» (Braverman, 1975: 112). Tras observaciones y cronometrajes minuciosos fueron construidos sistemas estándar en los que, no sólo se descompusieron los movimientos generales en sus componentes elementales, sino que se atendió incluso a elementos difíciles de secuenciar como son la velocidad y la aceleración de los movimientos humanos. Todo ello fue posteriormente sometido a la lógica y aritmética de las computadoras (p. 205-210)6. Según esto, es obvio que el desanclaje del tiempo de su contexto permitió trasladar el movimiento y el ritmo «naturales» de los cuerpos a un sistema abstracto de cronometraje, lo que permitió al canzar algunos de los objetivos del plan disciplinario que inspiró la modernidad.

Pero decía más arriba también que en la modernidad el tiempo se despegó de su referente cósmico. En efecto, si el reloj abstrajo el tiempo del viejo contexto social, la mecánica newtoniana intentó hacer lo propio respecto a los ciclos naturales. Y si el reloj fue el gran aliado de la organización disciplinaria

5. Para Lasalle (1828), por ejemplo, el acto de escribir requiere «tener el cuerpo un poco libre y vuel to del lado izquierdo, y un tanto inclinado hacia delante, de suerte que estando el codo apoyado sobre la mesa, la barbilla pueda apoyarse en el puño, a menos que el alcance de la vista no lo permita; la pierna izquierda debe estar un poco más adelante bajo la mesa que la derecha. $\mathrm{H}$ ay que dejar una distancia de dos dedos entre el cuerpo y la mesa; porque no sólo se escribe con más rapidez, sino que nada hay más perjudicial para la salud como el hábito de apoyar el estómago contra la mesa; la parte el brazo izquierdo desde el codo hasta la mano debe estar colocada sobre la mesa. El brazo derecho ha de estar al ejado del cuerpo unos tres dedos y sobresalir casi cinco dedos de la mesa, sobre la cual debe apoyarse ligeramente» (Foucault, 1975: 156).

6. En 1960 se editó en Estados Unidos una guía, que compilaba los datos estándar de las grandes compañías, en la que se incluía el trabajo de oficina. En esa guía se indicaba que abrir y cerrar el cajón de archivo costaba 0,04 minutos, levantarse de la silla 0,033 minutos, moverse en la silla para alcanzar un escritorio o archivero (4 pies máximo) 0,050 minutos, etc. (Braverman, 1975: 368). 
de la sociedad que impuso la modernidad, el tiempo de la mecánica newtoniana permitió el despegue de la ciencia clásica, lo que resultó ser de gran utilidad para los constructores de máquinas de la Revolución Industrial.

A finales del siglo XVI un nuevo concepto de tiempo iba a crearse en 0 ccidente como consecuencia del interés de $G$ alileo por explicar el movimiento de los objetos en el aire (M orris, 1989: 23-59). C uestionándose la tesis aristotélica de que el movimiento «natural» en caída de los objetos dependía de su peso, descubrió que la distancia recorrida en caída era proporcional al cuadrado del tiempo. N o obstante, quedó por resolver el problema de la aceleración, clave para la nueva concepción del tiempo, debido a que todavía no se conocía el cálculo infinitesimal. Leibniz y N ewton, en la segunda mitad del siglo XVII, y cada uno por su cuenta, lo inventaron. Con él se pudo medir las medias de velocidad instantánea según un coeficiente de variación entre tiempos determinados que podían ser reducidos a voluntad.

Esta nueva descripción del tiempo encajó perfectamentamente en el modelo mecanicista de N ewton. Según él, toda descripción dinámica implica dos tipos de datos empíricos: por un lado, la descripción de las posiciones y las velocidades de cada uno de los puntos de un sistema en un instante dado, a menudo llamado «instante inicial», por medio de un sistema de ecuaciones diferenciales, y, por otro, la naturaleza de las fuerzas dinámicas. Como de entre todas las fuerzas, a pesar de que se conocían más, sólo fue tenida en cuenta la gravitatoria, la descripción dinámica sólo resultó realmente determinada por el estado inicial. Esta indicación tuvo dos consecuencias. En primer lugar, y desde un punto de vista epistemológico, que para la ciencia clásica no hay sistema más que por referencia a un punto fijo a partir del cual tiene lugar el orden, y que la dinámica, al hacer de la reversibilidad la propiedad básica de todo cambio 0 evolución (Prigogine y Stengers, 1990: 90) - pues el principio de conservación de la energía (la ausencia por tanto de rozamientos, choques y contactos) hacía del sistema una máquina ideal perfecta— , abole el tiempo. Y en segundo lugar, desde un punto de vista sociológico, que, «siendo una de las fuentes del mecanicismo newtoniano el saber de los artesanos y constructores de máquinas medievales, ella misma da, al menos en principio, los medios para actuar sobre el mundo, prever y modificar el curso de ciertos procesos, concebir dispositivos y poner en marcha y explotar algunas de las fuerzas y de los recursos materiales de la natural eza» (Progogine y Stengers, 1990: 61-62), por lo que esta ciencia clásica, y con ella su concepción del tiempo, tienen más poder de manipulación (pues da lugar a un mundo trivial u ordenado ${ }^{7}$ en el que

7. Son «máquinas trivial es» según Foerster (1991: 148-54) gran parte de aquellos artefactos construidos por los hombres (como los el ectrodomésticos, ordenadores, automóviles, etc.) en los que conociendo su estado interno y las entradas nos resultan predecibles las salidas; y son «máquinas no triviales» gran parte de los artefactos naturales, en los que, puesto que el estado interno cambia con cada entrada, nos resultan impredecibles las salidas. D esde otro punto de vista y basándose en las relaciones entre la noción matemática de información y el cálculo de la entropía, Atlan (1990: 80-82) distingue el «orden», que «sólo aparece en una estructura si se la conoce», de la «complejidad», que se refiere a un sistema no del todo conocido. 
todo es predecible y por lo tanto controlable) que de comprensión. Q uizá este abusivo reduccionismo fuera la causa de que W illiam Blake exclamara: «ique dios nos guarde de ver con un sólo ojo y de dormir con el sueño de N ewton!»8.

En último término, aunque el serial ismo y la reversibilidad desanclaron el tiempo de sus referencias naturales y sociales instituyéndolo como objetivo, en realidad lo que hicieron fue ligarlo a unos nuevos paradigmas, los sostenidos por el reloj y el mecanicismo newtoniano, que permitieron, respectivamente, los anclajes del capitalismo, en su vertiente disciplinaria, y de la legitimación científica de la estabilidad.

\section{Dimensión imaginaria: del eterno retorno al utopismo}

La existencia del orden imaginario cuestiona el carácter arbitrario del signo saussureano en el sentido de que descubre determinaciones intrínsecas muy complejas entre sus dos lados, el significante y el significado. Si el significado remite en realidad a muchas constelaciones de significados virtual es (tal como se han encargado de mostrar el psicoanálisis de Jung, la antropología de D urand y el análisis de las religiones de Eliade, entre otros), el significante sólo suele actualizar y trivializar una o varias de ellas. Sin embargo, esta reducción del imaginario efectuada por el significante nunca es perfecta, pues a poco que el interesado indague, si empre se puede tener la oportunidad de reencontrar en el signo los significados imaginarios desplazados.

Según esto, será interesante comenzar esta aproximación a la dimensión imaginaria del tiempo comprobando, con D urand (1984), cómo el hombre ha intentado conjurar desde siempre, ya con sus primeros símbolos, el temido y huidizo devenir. Según su estudio de las estructuras antropológicas del ima ginario hay en principio un movimiento de abstracción y alejamiento de la materia que, en primera instancia, conjura el caos del devenir y de las tinieblas con los símbolos más arcaicos que se conocen pero que después se estabilizará manipulando otros más el aborados. Se vence al caos otorgándole rostros animales (principal mente el caballo y el toro, que reenvían a la alerta y huida del animal ante lo animado en general - p. 88- ) y femeninos (en los que el «agua negra» se convierte en la metáfora de la sangre menstrual, asociada al tiempo lunar, y dueña de la vida y de la muerte - p. 122-), o eufemizando la huida con el «mito de la caída» (quintaesencia de toda la dinámica de las tinieblas, a la que por transformación de la feminidad se asocia la carne sexual y digestiva). Y se impide el retorno del caos construyendo un sistema formado por símbolos que, a la vez, prolongan y sustituyen a los anteriores, entre los que se cuentan los «especulares» (entre ellos los «luminosos» que,

8. «Al precipitarnos en la reversibilidad, nuestras sociedades de trabajo y distribución de las horas y de los días intentan hurtarnos la muerte, hacernos olvidar o perder nuestros otros tiempos. Vivimos drogados de semejanza y de reversibilidad. Como se trata del tiempo de nuestro mundo, seguimos persuadidos de que nuestras organizaciones sociopolíticas imitan la economía del universo. Permanecemos acerrojados en esta armonía transparente» (Serres, 1991: 76). 
asociados a la palabra, darán protagonismo a la vista y al verbo, medios con los que será ordenado el mundo) y los «ascensionales» (que aluden a la reconquista de una potencia perdida, y lo hacen de tres maneras vecinas entre sí: «metafísicamente» - con las imágenes de ascensión o erección hacia un más allá del tiempo- - místicamente - con el vuelo de la «sublimación de la carne», en el que el ángel aparece como negación de la sexualidad- y vir-il o vir-tuosamente - con la fuerza del monarca, que reúne en sí originalmente las figuras del rey, el guerrero y el juez- ).

A esta huida del devenir en dos movimientos sucederá, ya tranquila la conciencia, un retorno sólo aparentemente materialista del que resultará una eufemización y hasta la antífrasis de los primeros rostros del caos. Así sucede en general con los «símbolos de inversión» y en particular con la feminidad (antes símbolo de las tinieblas y ahora loada por su fecundidad - p. 226-227- ), 0 la noche (redimida por el rico imaginario de místicos como san Juan o santa Teresa y románticos como G oethe o H ölderlin - p. 248-249).

En cierto modo, todo símbolo temporal, en tanto que resumen o síntesis de las imágenes del tiempo, resulta de las múltiples manipulaciones tanto idealistas como «materialistas» efectuadas por el espíritu humano. Pero en relación con la institución explícita de temporalidades imaginarias Ilevada a cabo con imágenes más abstractas y elaboradas nos encontramos con un imaginario muy particular que conjura más efectivamente el flujo del devenir y en el que se reconoce mejor el occidental. En primer lugar, con el tiempo reversible del eterno retorno, que remite invariablemente a la eternidad. Según ha mostrado Eliade (1992, 1994), las sociedades tradicionales, por el hecho de ser sociedades que animan el mito del eterno retorno, son sociedades contra el Tiempo, contra la $\mathrm{H}$ istoria9. En efecto, los mitos y rituales pertenecen al tiempo sagrado que actualiza el origen del acto cosmogónico primordial, lo que les sirve para abolir el tiempo profano y transportarse a la eternidad: «al recitar 0 al escuchar un mito, se vuelve a tomar contacto con lo sacro y con la realidad, y al hacerlo se supera la situación profana, la situación histórica» (1994: 63). Este tiempo histórico objeto de exclusión es en parte el profano, pero también tiene que ver muy especialmente con la temporalidad de los acontecimientos exteriores, imprevisibles y no deseados que, a menudo, afectan a la estabilidad e incluso a la supervivencia de la propia comunidad. Es por esto que la reversibilidad que instaura el eterno retorno para permanecer cerca de la eternidad, debe luchar contra la irreversibilidad de los acontecimientos no previstos que precipitan la caída en el tiempo. Pues bien, para resolver esta tensión entre el tiempo sagrado y el profano el pueblo judío, forzado por su trágica historia y haciendo de necesidad virtud, ejecutó una manipulación singular, la sacralización del tiempo histórico y su conversión en un tiempo

9. En general esa Iucha contra la H istoria, junto a las luchas contra la Política, la Ley y la Economía, no son sino distintas manifestaciones de la propiedad esencial de las sociedades primitivas: el «prohibir la autonomía de uno cualquiera de los subconjuntos que la constituyen» (Clastres, 1974: 180). 
escatológico, irreversible como la $\mathrm{H}$ istoria pero que, al igual que el eterno retorno, apuntaba a la eternidad ${ }^{10}$. M ás tarde, el salto mortal del cristianismo, que siguió aboliendo la historia, pues igualmente quería sal varla, culminó esta espiritualización del tiempo ubicando la eternidad y la salvación personales no en el futuro de los vivos, sino tras la muerte, y convirtiendo en beneficiarios de esa salvación eterna no a un pueblo sino a todos, a la humanidad. D ejó de este modo abiertas las puertas a la tercera imagen del tiempo, la del eschaton profano, que introducirá la modernidad a través del historicismo - «producto de la descomposición del cristianismo» según Eliade (1994: 182) - tras tomar conciencia de la muerte de dios y sustituir el imperativo religioso premoderno («mañana, cadáveres, gozaréis») por la máxima política de la modernidad («mañana gozaréis») (I báñez, 1994: 170), de la que resultará la construcción de utopías.

\section{D imensión pragmática: la sincronización}

Pasando a la dimensión pragmática de la institución social de la temporalidad en la modernidad, hay que comenzar señalando que, entre otras cosas, es la encargada de hacer distinciones e indicaciones de segundo orden (de tercero mejor, pues, como anotamos a pie de página, antes del tiempo/eternidad está el par ser/no-ser), con las que se señalan intervalos espaciotemporales distintos y jerarquizados, y de sincronizar unos con otros.

Una de esas distinciones, básica en toda sociedad, es la que instituye un continuo vital para los individuos y da lugar a la secuencia infanciaadolescencia-juventud/madurez/vejez en la que el lado indicado (o no marcado) es la madurez ${ }^{11}$, siendo la juventud un «todavía no» y la vejez un «ya no». Actualmente, como consecuencia del tipo de orden construido por el capitalismo, la «mayoría» adulta es paradójicamente cada vez menos numerosa y las «minorías» jóvenes y mayores cada vez más numerosas ${ }^{12}$. Por lo que respecta a los jóvenes, esto sucede porque el acceso a las responsabilidades laboral es y fami-

10. El eschaton, «lo que está fuera de alcance», es el tiempo de la «salvación», tanto sacra (la judeocristiana) como profana (la u-topia). El sentido del tiempo será desvelado en ese instante final o apocalipsis - «des-ocultar») (Galimbert, 1992).

11. Los ritos de iniciación de los adolescentes en las sociedades tradicionales, que implican una triple revelación - la de lo sagrado, la de la muerte y la de la sexualidad (Eliade, 1992: 158-161) - son por eso fundamentales, pues permiten conjurar el componente sal vaje asociado a esa edad y sincronizar sus vidas con las de la sociedad.

12. Como han señalado D eleuze y G uattari (1988: 107-08) la oposición cual itativa entre mayoría y minoría es más importante que la cuantitativa. La mayoría, desde un punto de vista cualitativo, implica una constante universal, «un metro-patrón con relación al cual se evalúa», y supone un estado de poder y dominación. En este sentido es evidente que el $\mathrm{H}$ ombre tiene la mayoría, incluso si es menos numeroso que los niños-adolescentes-jóvenes y las mujeres. Y la tiene porque como término no marcado aparece dos veces: una vez en la constante, como sistema (la humanidad), otra en la variable de la que se extrae la constante, como subsistema (opuesto a las mujeres y a los niños-adolescentes-jóvenes) (p. 107). Las minorías están, por esto, ontológicamente fuera del sistema. 
liares (incluidas las domiciliares, conyugales y paterno-maternofiliales) tiendea demorarse en el tiempo y, por lo tanto, la espera en la irresponsabilidad laboral (el desempleo y el estudio) y familiar (la condición de hijo dependiente) a prolongarse. Si en la edad media, salvo entre la aristocracia, a causa del temprano acce so al trabajo, la juventud era prácticamente inexistente, a finales del siglo pasado emergió una conciencia social sobre la adolescencia, a la que ha seguido en este siglo otra sobre la juventud (Galland, 1991: 9 y s.). La causa de esta última toma de conciencia es la masiva producción social de juventud efectuada por el capitalismo con la revolución científico-técnica (que prolonga el tiempo de formación profesional), la crisis del pleno empleo y la aplicación de políticas económicas neoliberales (que dificultan, respectivamente, el acceso al trabajo o la emancipación a través de él). Tan enorme ha sido la cantidad de juventud así producida que a la incorporación o «sincronización» tradicional (la del acceso a las responsabilidades) ha debido añadirse una sincronización de segundo orden que ya no tranforma a los sujetos imponiéndoles responsabilidades, sino que los reconstruye como «jóvenes» capturando, desactivando y orientando su jovialidad con proyectos institucionales o con la inestimable ayuda de la industria del ocio. Sin embargo, en cada sincronización no toda la jovialidad es capturada ni desactivada. Siempre quedará un resto del que los jóvenes se servirán para desbordar creativamente las coacciones o sugerencias apropiándose de ellas (Lefebvre, 1984: 111) e inventar nuevos estilos de vida. Así que se requerirá una nueva sincronización de la que otra vez excederá un resto... Y así indefinidamente.

Uno de los informes sobre la juventud española realizado por la Fundación Santa M aría (1984) lo formulaba más o menos del mismo modo. Se descubría que en el entorno de las rápidas transformaciones sociales y económicas experimentadas por la sociedad española, los adultos tendían a abandonar la cultura tradicional y a mimetizar la juvenil, de tal modo que la legalizaban, formalizaban y legitimaban como alternativa cultural. «Tal apropiación - se decía - implica mucho de manipulación y comercialización, lo que fácilmente empuja a los jóvenes a huir hacia delante en busca de nuevos modos expresivos» (p. 181). Sin embargo, es poca la jovialidad que huye y mucha la sincronizada. Como consecuencia de esto, hay veces que el sociólogo de la juventud se encuentra ante una situación extraña, la desaparición de su objeto de estudio: «H ay tipos de jóvenes que se parecen más a determinados adultos que al propio resto de los jóvenes [... ], es porque tales jóvenes sólo son jóvenes en términos demográficos, pero ya no lo son en términos sociales» (Gil Calvo y M eléndez Vergara, 1985: 256).

0 tro tanto puede decirse respecto a la distinción tiempo de ocio/trabajo. La complementariedad jerárquica en favor del trabajo indicada por la modernidad ha invertido la indicación original de la que nos informa la etimología del término latino otium, semánticamente previo a neg-otium13. Pues bien, siendo

13. U na vida social regulada por la indicación original, la que pone en primer término el ocio, es la de los uitoto, que dicen: «nuestras tradiciones están si empre vivas entre nosotros incluso cuando no danzamos; pero trabajamos tan sólo para poder danzar» (Eliade, 1992: 92). 
el tiempo del trabajo - como el de la madurez- uno de los relojes centrales de la sociedad moderna, no es extraño que el tiempo de ocio haya sido sincronizado por él. En primer lugar separando tajantemente con calendarios y relojes el trabajo del tiempo libre (algo inédito en la premodernidad), y después reconstruyéndolo según dos de las características más importantes del trabajo (G arcía Calvo, 1991): su carácter heterónomo (privación del dominio sobre lo que se hace) 14 y sus efectos castradores (privación del placer presente obtenido con lo que se hace) ${ }^{15}$. Respecto a esto último, conviene recordar que en el otium, como sucede en el juego, «no se trata de conseguir nada al final sino de sacar gusto en cada momento» de su práctica, por lo que «cada instante está en sí mismo» y no «en función del anterior, ni del posterior, ni menos aún de un final, de un logro» (Sánchez Ferlosio, 1992).

Pues bien, castrar el tiempo libre exige, como en el trabajo, que ese vivir en estado bruto liberado por la actual «revolución cultural del tiempo libre» (D umazi dier, 1988) sea orientado y aprovechado por la sociedad instituida según un ritmo o calendario, e incluso un método, para afianzar su orden. Eso es precisamente lo que se hace cuando el mercado de bienes y servicios captura el componente de subjetivación hedonista y hace competir a los sujetos y a las clases en los ciclos de distinción y divulgación social de gustos. D e ese modo se crean modas que permiten a la esfera económica producir ininterrupidamente y a la cultura homogeneizarse (Simmel, 1927). Sin embargo, Bourdieu (1991: 98) ha observado que los consumidores también colaboran en la producción cultural otorgando sentidos nuevos a los objetos que consumen. Se trata de suplementos de sentido no instituidos, producidos desde la competencia sociocultural de clase, etnia, género, etc. que cada consumidor posee. Este reciclaje de los objetos protagonizado por los consumidores dará lugar a formas culturales «híbridas» (G arcía C anclini, 1989: 263 y s.), que están a la vez dentro y fuera de la sociedad instituida. Pero los magos del marketing se interesarán por ese exceso de sentido, por esa anamnesis de sociabilidades residuadas, y producirán relatos publicitarios e incluso nuevos objetos para encadenar de nuevo el deseo, volver a homogeneizar la cultura y dar otro respiro a la esfera productiva. Y así indefinidamente16.

14. Antes del siglo XVI se utilizaban los términos laborare y poneros para designar la actividad cotidiana de campesinos y artesanos, pero pronto esa forma de ocuparse de las necesidades fue sustituida por el trabajo. $\mathrm{H}$ ay en esta actividad una coacción de la que nos informa la eti mología del término, pues «trabajo» es un sustantivo derivado del verbo latino trepaliare que en el siglo vı significaba, «torturar sobre el trepalium», armazón de tres troncos que en el mundo cristiano reemplazó como suplicio a la cruz (Illich, 1978: 53).

15. En último término trabajar consiste en repetir una y otra vez actos predeterminados en un tiempo del que el presente es evacuado, y sólo sirve para que quien lo ejecuta no reciba placer ni beneficio inmediato al guno sino dinero, o lo que es lo mismo, «una cantidad de fe en que se puede cambiar por cosas, con tal de que éstas no tengan mucha cosa sino más bien idea de cosa» (G arcía C alvo, 1991: 81-82).

16. Es importante constatar que, en el caso de la jovialidad y del tiempo libre, no está garantizado que la sincronización efectuada por los rel ojes centrales de la sociedad resulte del todo 
A la vista de los dos ejemplos se puede concluir que la dimensión pragmática de la temporalidad moderna alude a un doble movimiento: el de la sincronización que cierto reloj central y arbitrario de la sociedad efectúa de las temporalidades de la socialidad según un plan trascendente y unidimensional, y el de las fugas y desterritorial izaciones protagonizadas constantemente por los restos no sincronizados ${ }^{17}$. Este vaivén entre el orden y la disipación puede durar indefinidamente.

\section{Del tiempo instituido moderno al tiempo instituyente postmoderno}

Si algo queda claro después de este repaso a lo más llamativo de las dimensiones referencial, imaginaria y pragmática del tiempo de la modernidad es que es objeto de un control especial por parte de la «sociedad instituida». Sin embargo, si cambiamos el puesto de observación y nos ubicamos en las «socialida des instituyentes», es obvio que el objetivo del análisis deja de ser cómo se reproducen y mantienen las desgastadas estructuras temporales modernas y pasa a serlo cómo se rompe con ellas y se efectúa (o puede efectuarse) la apropiación del devenir ${ }^{18}$. Para que este cambio tenga lugar, parece haber dos

efectiva, pues siempre quedará un residuo que logrará manifestarse en cada ocasión que un objeto propuesto aliene al sujeto. Es lo que sucede con el «goce» del deseo (Alemán, 1988), según el psicoanálisis lacaniano, cuando se liga a objetos con los que el sujeto pretende colmar la pérdida originaria. Aunque siempre resultará alienado, en cada caso la «pulsión de muerte», el movimiento reactivo de lo residuado por la vida, tendrá la oportunidad de aparecer y manifestarse. Pues bien, con la jovialidad y el querer vivir del tiempo libre sucede lo mismo. D e ahí que, también en estos casos, se pueda afirmar que para cada alienación siempre hay un resto, un suplemento de sentido, relativo a al go bien distinto de lo que el orden instituido es. Pero esa otra cosa, como no cabe del todo en el registro del orden en que es inscrito y pensado, sólo aparece como negatividad, permanente desfinatación y desdefinición de lo instituido y su modo de pensar.

17. O tro ejemplo de sincronización fallida: «H ace tiempo que se viene estudiando el equívoco que cuarteaba por dentro el "triunfo" de los colonizadores españoles con respecto a las colonias autóctonas: con frecuencia esos indios sumisos, e incluso consintientes, hacían con las liturgias, las representaciones o las leyes que se les imponían, otra cosa distinta de lo que el conquistador creía conseguir a través de ellas; las subvertían, no rechazándolas o cambiándolas, sino utilizándolas de una manera, con unas finalidades y en función de unas referencias extrañas al sistema del que no podían escapar. Eran distintos desde lo más profundo del orden que los asimilaba exteriormente; esos indios se le iban de la mano al conquistador pero sin abandonarlo. La fuerza de su diferencia estaba contenida en los procedimientos de consumo» (Certeau, 1990: XXXVII-XXXVIII).

18. La distinción «sociedad instituida»/ «socialidades instituyentes» la formulo inspirándome en M affesoli y Lourau. En opinión del primero (M affesoli, 1985: 16), conviene distinguir «o social» (que yo denomino «sociedad instituida»), formado por el conjunto de relaciones racionales y mecánicas que se establecen entre los individuos y que son sancionadas por las ideologías, de la «socialidad», «expresión cotidiana y tangible de la solidaridad de base, lo societal en acto». D el mismo modo, Bataille (1993: 10 y s.) distinguió «a parte homogénea» de lo social, en la que «las relaciones humanas pueden mantenerse por una reducción a reglas fijas basadas sobre la conciencia de la identidad posible entre personas y situaciones 
opciones: una global de carácter macro, la revolución (en la que espontáneamente tienen lugar éstas y otras apropiaciones), y dos parciales de carácter micro que pasan o por inventar nuevas distinciones para cada dimensión del tiempo (algo sólo posible con gol pes de genio imprevisibles), o por aprovechar las efectuadas por la modernidad y pasar del lado indicado a otros. En relación con este último cambio, el menos rupturista de todos, es posible prever el paso de la reversibilidad estática a la irreversibilidad dinámica en la puntuación del paradigma que resume la dimensión referencial, del eschaton al presente en la puntuación de la dimensión imaginaria, pero sobre todo de la sincronía a la asincronía en la puntuación de la dimensión pragmática. D aré al gunas pistas sobre el alcance de estas rupturas.

\subsection{Cambio de referencias: de los si stemas estables a los metaestables 0 alejados del equilibrio}

Empecemos por el cambio de puntuación, o de paradigma, en la dimensión referencial. La reversibilidad estática newtoniana, que impedía pensar y construir el cambio social, fue superada en el siglo XIX por la irreversibilidad estática del segundo principio de la termodinámica. Según esa ley, cualquier sistema parece tender a morir o degradarse, bien perdiendo energía, bien perdiendo la organización de sus estados internos. Este principio superaba el mecanicismo clásico, ya que hacía posible la descripción de los sistemas dinámicos y permitía la aparición del tiempo. Sin embargo, fallaba al considerar simplemente los cambios orientados hacia el estado global más probable, la muerte térmica de los sistemas o la equiprobabilidad de todos los microestados internos, pues estaba claro que lo vivo había emergido de lo físico desafiando precisamente esa ley y que con lo social había sucedido lo mismo al despegarse de lo vivo. Schrödinger (1986: 97-98), reinterpretando el segundo principio, sugirió respecto a la improbabilidad de la vida que un sistema se mantenía vivo y aleja-

definidas», y la «existencia social heterogénea», formada por elementos imposibles de asimilar. Lourau (1988: 90), con el par «nstituido/instituyente, permite añadir tensión y dinamicidad a la distinción sociedad (parte homogénea)/socialidad (parte heterogénea): «en épocas normal es lo social se manifiesta en la institución pero esta manifestación es verdadera y a la vez falaz, en cierto modo, como lo indican los momentos en que lo social instituyente irrumpe y emprende su taea sin intermediarios, los momentos de revolución»; «esta tarea apunta a un resultado, darse de nuevo una institución para existir en ella de manera visible», pero que cuando esta institución queda de nuevo planteada, «lo social instituyente se aparta, toma distancia, se encuentra otra vez en otro lado». U na dinámica idéntica, pero más general, entre un «plano de consistencia» (el de los procesos psíquicos y sociales primarios o heterogéneos) y otro de «inmanencia» (relativo a los secundarios o heterogéneos), ha sido realizada por D eleuze y G uattari (1988: 74 y 268-74): «el plan de organización no cesa de actuar sobre el plan de consistencia, intentando bloquear siempre las líneas de fuga, detener o interrumpir los movimientos de desterritorialización [... ] Y, a la inversa, el plan de consistencia no cesa de extraerse del plan de organización, de hacer que se escapen partículas fuera de los estratos» (p. 272). 
do del equilibrio termodinámico intercambiando la entropía positiva o desorden producido en el interior del sistema por entropía negativa u orden extraído del entorno o ecosistema. Esta lógica parasitaria se observa también dentro mismo de los sistemas sociales, pues han afirmado su también milagrosa existencia escindiéndose en partes de tal modo que unas dominan y otras resultan ser dominadas, convirtiéndose las primeras en sistema y las segundas en mero ecosistema (I báñez, 1990).

La lógica del intercambio de entropías propuesta por Schrödinger, que es también la lógica de la ordenación de lo social en la modernidad, está siendo sustituida por un modo distinto de explicar cómo se conjura el segundo principio de la termodinámica, y con él el peligro de la muerte, el modelo de las «estructuras disipativas», que puede dar lugar a estilos de vida ecológica y socialmente sostenibles. Según las investigaciones de Prigogine y su equipo relativas a la ontogénesis de los sistemas, la emergencia de los órdenes que conjuran el segundo principio de la termodinámica sólo puede darse en sistemas abiertos altamente inestables 0 alejados del equilibrio. En efecto, en un «orden por fluctuaciones» alejado del equilibrio (Pigogine y Stengers, 1990: 199 y s.) si una fluctuación microscópica ha superado una amplitud e intensidad críticas y ha sido también capaz de contrarrestar los efectos amortiguadores del sistema en su conjunto, a partir de cierta distancia del equilibrio puede generar «fenómenos de autoorganización espontánea, rupturas de simetría [y] evoluciones hacia una complejidad y diversidad crecientes» (p. 299). En cada fluctuación el horizonte de sucesos se encuentra abierto a la producción de novedad y a la ruptura 0 «bifurcación» hacia estados estadísticamente improbables, por lo que la historia del sistema no está ya de ningún modo dada de antemano sino que resulta imprevisible. Las investigaciones indican que en las bifurcaciones de los sistemas metaestables las características de lo nuevo no serán siempre idénticas, pues dependerán de cómo surgió la fluctuación. $\mathrm{H}$ ay por lo tanto «sensibilidad a las condiciones iniciales», así que cada bifurcación tiene su propia historia. El modelo de las estructuras disipativas sugiere también que un sistema se mantendrá alejado del equilibrio termodinámico, y por ello de su muerte, no tanto explotando y degradando el entorno como siendo capaz de reciclar la entropía positiva o desorden interno producido.

Este paradigma resulta de gran utilidad porque puede permitir describir con más tino lo que realmente sucede en los conflictos sociales y prever la aparición de modos de emancipación política distintos a los ensayados hasta ahora. Si hacemos caso a Bataille (1993: 3-7), la conciencia revolucionaria surge, antes que de cualquier proyección escatológica, de la desesperante experiencia de una conciencia desgarrada por la certidumbre de la muerte o la desgracia posibles. Lo importante es que en ese original desorden «el porvenir no descansa sobre los minúsculos effuerzos de al gunos agrupadores dotados de un optimismo incorregible: depende por completo de la desorientación general». Si esto es así quizá el rupturismo postmoderno, tras el derrumbe de las grandes ideologías, ensaye un modo de liberarse de la sociedad instituida que 
se tome en serio las propiedades autoorganizadoras del desorden y prescinda definitivamente de los líderes, vanguardias y otros agentes estabilizadores. EI paso previo parecen estar dándolo los denominados «nuevos movimientos sociales».

\subsection{Cambio de imágenes: del futuro al presente}

En segundo lugar, hoy también resulta posible para el rupturista, tras la desaparición de las utopías y la manifestación desnuda de la tragedia del existir, pasar a vivir afectivamente el tiempo creando y recuperando sociabilidades que giren en torno a imágenes valorizadoras del presente. H eidegger (1993: 253 y s.) desenmascaró el optimismo historicista de la modernidad mostrando que el «ser ahí » es «una constante no totalidad que encuentra su fin con la muerte». Aunque de ese funesto fin temporal tenemos la certidumbre de que es posible a cada instante, el ser-ahí no suele afrontarla esperando, como propone $\mathrm{H}$ eidegger, ni suele dejar tampoco brotar miedo ni angustia ante ella, sino que se tranquiliza ( «se cura») conjurándola mediante el cálculo y la publicidad. A pesar de mantener la irreversibilidad del eschaton sagrado y profano, el tiempo recuperó con esta formulación existencialista el aspecto terrorífico que tenía en las filosofías india y griega del eterno retorno (Eliade, 1992: 100) por su carácter indeterminado e imprevisible.

La tragedia que $\mathrm{H}$ eidegger descubrió tras el velo de los futuros reconfortantes, y que actual mente resulta más visible con la crisis de los metarrelatos ideológicos modernos, obliga a producir imágenes que permitan afrontar la finitud de la existencia en el presente, sin diferir el goce a ningún otro tiempo. Es lo que parece estar sucediendo, si hacemos caso a M affesoli (1985), con el retorno de D ionisos (y sus sociabilidades orgiásticas) tras la pérdida de credibilidad del laborioso Prometeo. Por otro lado, quizá la individual idad trágica postmoderna apueste también por el rescate del kairos griego, intervalo temporal en el que el «pasado reciente» «confiere al presente las condiciones para obrar sobre el inmediato futuro» (Galimbert, 1992), y de este modo sustituya las acciones estratégicas por las tácticas ${ }^{19}$. Y para los menos apegados a la materia quizá seduzca el ksana, término sánscrito que, según Eliade (1994: 86-96), alude a un «presente total», el del éxtasis místico, que el monje budista produce provocando una «ruptura de niveles» por la que se libera del devenir y se transporta directamente a la eternidad. Aunque muy distintos en cuanto a contenido, el orgiasmos, el kairos y el ksana son tres imágenes que, al contrario de lo que sucede con el imaginario moderno, no separan al sujeto de la expe-

19. Como ha observado Certeau (1990: 57-63), la diferencia entre ambas clases de acciones estriba en que si una, la estratégica, subordina la temporalidad a un lugar y produce así un futuro estable, la táctica se desenvuelve en una temporalidad sin lugares que da protagonismo al presente. Además, la primera inspira el mando, pertenece entonces a los poderosos, mientras que la segunda da lugar al ardid, la artimaña, y la suelen utilizar los dominados. 
riencia presente del vivir y pueden seducir a las subjetividades postmodernas tras el derrumbe del futuro.

\subsection{Cambio de praxis. de la sincronía a la asincronía}

Por último, pasar de la sincronía a la asincronía en la dimensión pragmática del tiempo supone pasar de un orden en el que los sucesos son secuenciales (por estar controlados por el mismo reloj) a otro en el que sean realmente concurrentes (que aunque los sucesos coincidan se mantenga la existencia de relojes diferentes)20. Según la teoría de redes de Petri (N avarro, 1994), se dice que hay «concurrencia conflictiva» cuando dos sucesos comparten al menos o una precondición (y no sabemos qué pasará) o una postcondición (y no sabemos qué pasó). Si la resolución del conflicto pasa por la elección de la ocurrencia de uno de los sucesos, el agente que tenga el poder de realizar esa elección decidirá el deber ser del sistema: qué sucedió en la $\mathrm{H}$ istoria o que sucederá en el Futuro. Un conflicto entre sucesos asíncronos concurrentes resuel to de este modo es entonces producto de una sincronización heterónoma y el imperativo ético que aś se promueve es del tipo «tú debes... » (0 «tú debiste» 0 «tú deberás»). Este tipo de máximas heterónomas no hacen sino negar la competencia social de los actores para resolver sus conflictos. Ahora bien, los sistemas vivos y sociales, a pesar de poder ser manipulados desde fuera, antes que nada son sistemas organizacional mente cerrados e informativamente abiertos: pueden controlarse desde dentro gracias a las múltiples sincronizaciones que acuerdan los actores para encontrar soluciones y son capaces de producir información inédita (I báñez, 1990). C omo, por otro lado, la salud y supervivencia de un sistema (sea éste la materia, lo vivo, lo social o cualquiera de sus partes) depende en último término del abanico de estados internos que es capaz de aceptar (Foerster, 1991; Atlan, 1990), un actor realmente comprometido con él está obligado a resolver sus conflictos según un principio ético autónomo del tipo: «yo debo actuar siempre como para incrementar el número total de alternativas» (Foerster, 1991: 120). Precisamente lo que el control externo hace con su intervención heterónoma es impedir que este tipo de autoorganización funcione ${ }^{21}$. Por lo tanto, pasar de la secuencialidad de sucesos impuesta por un reloj a la concurrencia de sucesos gobernados por relojes diferentes exige de las socialidades instituyentes la conquista o invención de su autonomía. Sólo así los poderes de la edad adulta, del tiempo de trabajo y de otros relojes centrales pueden ser

20. N o tengo en cuenta la asincronía relativa a los sucesos copresentes porque, aunque están ordenados por relojes diferentes, los sucesos no coinciden. Es el caso de los sucesos físicos que, situados dentro y fuera del al cance de un cono de luz dado (el haz de luz como reloj), no tienen ninguna relación. U n ejemplo: puesto que la luz del sol tarda en llegar a la tierra ocho minutos, si el Sol estallara, ese suceso sería copresente o no existente para nosotros hasta ocho minutos después.

21. Y uno de los actores sociales que tiene la función de robar la información producida en la base y de enviarla a los dominios del Estado y del Capital para que el control que se ejecuta sea cada vez más efectivo es justamente la investigación social (Ibáñez, 1990: 188-93). 
relativizados por los afectados, y las manipulaciones de la jovialidad, el ocio y otros residuos, eliminadas. Q uizás las contemporáneas luchas por afirmar ciertas diferencias frente a los poderes heterónomos (caso del feminismo, del etnicismo, de las tribus, etc.) formen parte de esta emergente, enriquecedora y liberadora estrategia asincrónica.

\section{Bibliografía}

Alem Án, J. (1988). «G oce». En Reyes, R. (dir.). Terminología científico social. Aproximación crítica. Barcelona: Anthropos, p. 438-441.

ATLAN, H . (1990). Entre el cristal y el humo. M adrid: D ebate.

Bataille, G . (1993). El estado y el problema del fascismo. Valencia: Pre-textos y Universidad de Murcia.

Bo URDIEU, P. (1991). La distinción. Criterio y bases sociales del gusto. M adrid: Taurus. Braverm AN, H . (1975). Trabajo y capital monopolista. M éxico: N uestro Tiempo.

CASTRORIADIS, C. (1989). La institución imaginaria de la sociedad. Vol. 2, el imaginario social y la institución. Barcelona: Tusquets.

Certeau, M. de (1990). L'invention du quotidien 1. Arts defaire. París: Gallimard.

Cioran, E. (1988). Adiós a la filosofía y otros ensayos, M adrid: Alianza.

CLASTRES, P. (1974). La societé contre l'É tat, París: M inuit.

Deleuze, G.; G uattari, F. (1988). M il mesetas, esquizofrenia y capitalismo. Valencia: Pre-textos.

D U m AZIDIER, J. (1988). Revolution culturelle du temps libre(1968-1988). París: M eridiens Klinsieck.

Durand, G . (1984). Estructures antropologiques de l'imaginaire, París: D unöd.

ELIADE, M . (1992). El mito del eterno retorno. M adrid: Alianza.

- (1994). Imágenes y símbolos, Barcelona: Planeta-Agostini.

Foerster, H. von (1991). Las semillas de la cibernética. M adrid: G edisa.

Fou CAULT, M. (1986). Vigilar y castigar. M adrid: Siglo XXI.

García Calvo, A. (1991). N oticias de abajo. Zamora: Lucina.

- (1993). Contra el Tiempo. Zamora: Lucina.

García Can CLIN I, N . (1989). Culturas híbridas. Estrategias para entrar y salir de la modernidad. M éxico: Grijalbo.

G ALIM BERT, G . (1992). «La metamorfosis de crono». Archi piélago, 10-11, p. 55-58, Pamplona-I ruña: Pamiela.

Gallan D, O . (1991). Sociologie de la jeunesse, París: Armand Colin.

GIDDENS, A. (1993). Consecuencias de la modernidad. M adrid: Alianza.

Gil Calvo, E.; M elÉn D EZ Vergara, E. (1985). 0 cio y prácticas culturales de los jóvenes. M adrid: Instituto de la Juventud.

H EIDEGGER, M . (1993). Ser y Tiempo. Barcelona: Planeta-Agostini.

IBÁÑEZ, J. (1990). Nuevos avances en la investigación social. La investigación social de segundo orden. Barcelona: Anthropos (Suplementos, 22).

- (1994). Por una sociología de la vida cotidiana. M adrid: Siglo XXI.

ILLICH, I. (1978). La convivencialidad. Barcelona: Barral.

Keen ey, B.O . (1987). La estética del cambio. Barcelona: Paidós. 
LAO T SE (1985). Tao te ching. Barcelona: O rbis.

LefeBVRE, H . (1984). La vida cotidiana y el mundo moderno. Madrid: Alianza.

LYOTARD, J.-F. (1987). La condición postmoderna. M adrid: Cátedra.

LourAu, R. (1988). El análisisinstitucional. Buenos Aires: Amorrortu.

M AFFESO LI, M . (1985). L'ombre de D yonisos. Contribution à une sociologie de l'orgie,

París: Librairie des M eridiens.

M ORRIS, R. (1989). Las flechas del tiempo. Barcelona: Salvat.

N AVARRo, P. (1994). El holograma social. Por una ontología de la socialidad humana.

$M$ adrid: Siglo XXI.

PARM ÉNIDES/H ERÁClito (1983). Fragmentos. Barcelona: Orbis.

Prigogine, I.; Sten Gers, I. (1990). La nueva alianza. M etamorfosis de la nueva ciencia. M adrid: Alianza.

Sánchez Ferlosio, R. (1992). «uegos y deportes». El País, 9 de agosto de 1992.

SANTA M ARÍA, F. (1984). Informe sociológico sobre la juventud española. M adrid: Ediciones S.M.

SCHRÖDINGER, E. (1986). ¿Q ué es la vida? Barcelona: O rbis.

SerRes, M . (1991). El paso del noroeste. M adrid: D ebate.

SIM M EL, J. (1923). «Filosofía de la moda». Revista de 0 ccidente, 1. M adrid: Calpe, p. $42-66$. 